\title{
Eating the right amount of fish: Inverted U-shape association between fish consumption and cognitive performance and academic achievement in Dutch adolescents
}

Citation for published version (APA):

De Groot, R., Ouwehand, C., \& Jolles, J. (2012). Eating the right amount of fish: Inverted U-shape association between fish consumption and cognitive performance and academic achievement in Dutch adolescents. Prostaglandins, Leukotrienes, and Essential Fatty Acids, 86(3), 113-117.

https://doi.org/10.1016/j.plefa.2012.01.002

DOI:

10.1016/j.plefa.2012.01.002

Document status and date:

Published: 01/03/2012

Document Version:

Peer reviewed version

Document license:

CC BY-NC-ND

Please check the document version of this publication:

- A submitted manuscript is the version of the article upon submission and before peer-review. There can be important differences between the submitted version and the official published version of record. People interested in the research are advised to contact the author for the final version of the publication, or visit the DOI to the publisher's website.

- The final author version and the galley proof are versions of the publication after peer review.

- The final published version features the final layout of the paper including the volume, issue and page numbers.

Link to publication

\section{General rights}

Copyright and moral rights for the publications made accessible in the public portal are retained by the authors and/or other copyright owners and it is a condition of accessing publications that users recognise and abide by the legal requirements associated with these rights.

- Users may download and print one copy of any publication from the public portal for the purpose of private study or research.

- You may not further distribute the material or use it for any profit-making activity or commercial gain

- You may freely distribute the URL identifying the publication in the public portal.

If the publication is distributed under the terms of Article $25 \mathrm{fa}$ of the Dutch Copyright Act, indicated by the "Taverne" license above, please follow below link for the End User Agreement:

https://www.ou.nl/taverne-agreement

Take down policy

If you believe that this document breaches copyright please contact us at:

pure-support@ou.nl

providing details and we will investigate your claim.

Downloaded from https://research.ou.nl/ on date: 26 Apr. 2023 


\section{Eating the right amount of fish:}

\section{Inverted U-shape association between fish consumption}

\section{and cognitive performance and academic achievement in}

\section{Dutch adolescents}

R.H.M. de Groot ${ }^{1,2,3}$, C. Ouwehand ${ }^{2}$, and J. Jolles ${ }^{2}$

${ }^{1}$ Centre for Learning Sciences and Technologies, Open University, Valkenburgerweg 177, 6419 AT Heerlen, The Netherlands

${ }^{2}$ LEARN! Research Institute, Faculty of Psychology and Education, VU University Amsterdam, Van der Boechorststraat 1, 1081 BT Amsterdam, The Netherlands

${ }^{3}$ School for Mental Health and Neuroscience (MHeNS), Department of Psychiatry and Neuropsychology, Maastricht University, P.O. Box 616, 6200 MD Maastricht, The

Netherlands

\section{Corresponding author}

Renate de Groot

Centre for Learning Sciences and Technologies, Open University

Valkenburgerweg 177

6419 AT Heerlen, The Netherlands

phone: $\quad+31455762276$

fax: $\quad+31455762200$

email: $\quad$ Renate.deGroot@ou.nl

Financial support

This study has not been externally supported

Declaration of interest

None 


\section{ABSTRACT}

Fish consumption has shown its benefits for cognitive functioning in the elderly or children with disorders (e.g, autism, ADHD), but has rarely been investigated in relation to cognitive performance and school performance of healthy adolescents. Therefore an observational study in 700 Dutch high school students aged 12-18 years was executed. Fish consumption data, end term grades, scores on the Amsterdam Vocabulary Test, and scores on the Youth SelfReport were collected. Results revealed that $13.6 \%$ of the Dutch adolescents never ate fish, $6.4 \%$ met national guidelines, $16.9 \%$ reached half of the recommended amount, and $63.1 \%$ did eat fish but too little to meet at least half of the recommended amount. Analysis of variance, controlled for relevant covariates, showed significant differences between the four fish consumption groups in vocabulary $(p=0.05)$. A trend for significance was found for end term grades $(p=0.07)$. Contrast analyses demonstrated significant quadratic associations between fish consumption and vocabulary $(p=0.01)$ and end term grades $(p=0.01)$. Thus higher fish intake was associated with more advanced vocabulary and higher end term grades. However, eating more fish than the described recommended amount seemed no longer beneficial. 


\section{INTRODUCTION}

An increasing number of health benefits are attributed to the omega-3 long-chain polyunsaturated fatty acids (LCPUFA) present in fish. Not only the associations with cardiovascular diseases and mental diseases received attention in the past, but also the field of cognitive performance attracted interest. The fact is that n-3 LCPUFA docosahexaenoic acid (DHA, 22:6n-3) and eicosapentaenoic acid (EPA, 20:5n-3) are involved in many aspects of brain functioning including neuronal membrane fluidity, neurotransmission, signal transduction and blood-brain barrier function [1]. There are indications that consumption of omega-3 LCPUFA plays a protective role in age-related cognitive decline [2], as well as in cognitive disorders such as Alzheimer's disease [3]. In premature babies, it has been shown that higher omega-3 LCPUFA consumption is associated with better cognitive development [4], and in children, consumption of these fatty acids might lead to improvement of symptoms associated with disorders such as autism and ADHD [5]. Although previous research has not established conclusive evidence, it does suggest that in certain sensitive periods, omega-3 LCPUFA might contribute to the prevention of cognitive decline and to the optimization of cognitive performance and/or cognitive development.

The period of adolescence was, until recently, rather neglected in this scientific field though it has been shown that the brain of adolescents, and especially the prefrontal cortex, continues to mature until their late twenties [6]. This period of brain maturation forms the basis of the development of the higher order cognitive functions as well as social and emotional behavior. Because of the continuing brain development during adolescence, it is important to take into account the role of the omega-3 LCPUFA, not in the last place because the omega-3 LCPUFA DHA and EPA are important structural components of the neural cell membranes and influence in this respect membrane fluidity and signal transduction [7, 8]. Moreover, higher 
DHA intake has recently been associated with changes in the functional activity of the prefrontal cortex [9].

To our knowledge, there are only two studies, which highlight the effect of omega-3

LCPUFA intake on cognitive functioning during adolescence. Kim and colleagues showed that 15 years old adolescents who regularly consumed fish rich in omega-3 LCPUFA had significantly better academic performance than their non- or less fish consuming counterparts [10]. Aberg et al. demonstrated that high fish consumption in boys at age 15 was associated with better cognitive performance at age 18 [11].

In the current study, it is endeavored to extend these recent findings in a Dutch high school population with a broader age range and including both girls and boys. In addition to academic achievement, it is investigated whether DHA/EPA intake through fish consumption is associated with both objective and subjective current cognitive performance measured with, respectively, a vocabulary test and self-reported attention. In this way, new and important information about the role of omega-3 LCPUFA for cognitive development during normal adolescence is contributed. This was done through a large-scale observational study in almost 700 healthy Dutch high school students aged 12-18 years. Data with respect to fish consumption were collected as well as end term grades to determine academic achievement, scores on the Amsterdam Vocabulary Test, and scores on the Youth Self-Report. 


\section{METHODS}

\section{Design}

This study was part of a larger study investigating developmental aspects of several cognitive functions of adolescents and their interaction with sex and level of education. For this study, data on fish intake were compared with cognitive performance and academic achievement. The Ethical Committee of the VU University Amsterdam approved the research protocol.

\section{Procedure}

Before the start of the study, all students received an information letter about the study. They were asked to take the letters home to also inform their parents and/or guardians. Participation was voluntary and without reimbursement. Both adolescents and their parents/guardians had to provide written permission for participation. Next, testing in class was scheduled one week after distribution of the information letters and the informed consent forms. Those students meeting the informed consent requirement were tested simultaneously in the classroom by two trained psychologists, while their non-participating classmates worked silently on an assignment given by the teacher. Completion of all questionnaires and tests took approximately 40 minutes. In addition, the parents/guardians of the participating students filled in a questionnaire regarding their adolescent's development, lifestyle factors (e.g., fish consumption), and the socio-demographic background of the adolescent's family.

\section{Participants}

Participants were recruited from four secondary schools in the south of the Netherlands. All participants were in grades 7 through 12 and followed one of the two highest educational tracks in Dutch secondary education: 5-year higher general secondary education or 6-year pre-university education. These two tracks contain $40 \%$ of all students in secondary school. In 
order to be included in the study, participants had to be healthy. Participants suffering from learning, psychiatric or developmental disorders, using medication that might influence cognitive functioning, and/or skipping school regularly were excluded from the study. In addition, adolescents who took fish oil supplements were also excluded to be able to examine the exclusive association between fish intake and performance.

\section{Measures}

\section{$\underline{\text { Fish consumption }}$}

Fish consumption was measured by a validated self-report questionnaire (for further details, see [12]), which was filled in by the parents/guardians of the participants. They rated the frequency (never, once a month, two to three times per month, once a week, more often than once a week) of three types of fish consumption. These fish types were categorized according to their respective DHA/EPA contents as mentioned in the Dutch Food Composition Tabel 2003 [13]: low (fish fingers, prawns, pickled herring, mussels, cod, plaice, tuna and tilapia); intermediate (trout, raw herring, smoked eel, smoked salmon, canned salmon); and high (smoked herring, herring in tomato sauce, mackerel, canned sardines, salmon). An estimated average DHA/EPA intake per week was calculated. According to the Dutch 'guidelines for healthy food' [14], the recommended average DHA/EPA intake is $450 \mathrm{mg}$ per day which yields an average of $3150 \mathrm{mg}$ per week. Based upon this, participants were divided in four groups: (1) never eats fish, (2) DHA/EPA intake of less than $1575 \mathrm{mg}$ per week (i.e., less than half of the recommend amount), (3) DHA/EPA intake of a minimum of $1575 \mathrm{mg}$ per week, but less than the recommended amount, and (4) DHA/EPA intake of 3150mg per week or more.

\section{$\underline{\text { Vocabulary }}$}


Vocabulary of four types of words was assessed with the Amsterdam Vocabulary Test (for details, see [15]), which consists of 35 words of which five are concrete nouns (e.g., tool, island), ten are abstract nouns (e.g., initiative, point of view), ten are adjectives (e.g., reluctant, transparent), and ten are verbs (e.g., refuse, collect). The items were randomly ordered. For each item, participants chose one of the three options for explaining the meaning of that particular word. An overall score for vocabulary was calculated by summing the number of correct responses.

\section{$\underline{\text { Attention }}$}

To determine attention, participants filled in the attention subscale of the Dutch version of the Youth Self-Report [16], a self-report questionnaire derived from the CBCL which has been shown to have good reliability and validity. It consists of nine items measured on a 3-point Likert scale (Cronbach's alpha=.76). A higher score means that the participant has more selfreported attention problems.

\section{$\underline{\text { Academic performance }}$}

To determine academic performance, end of term grades for the three core school subjects Dutch, English and Mathematics were acquired from the school administration. The scores can range from 1 (very bad) to 10 (outstanding). Dutch, English, and Mathematics are mandatory for all students and are regarded by the Dutch government as essential for success in further education. Since schools may have differed in grading policies, standardized $z$ scores were calculated. Academic performance was operationalized as the standardized mean grade for the three core school subjects.

\section{$\underline{\text { Background variables }}$}

In a questionnaire filled in by the parent/guardian, information was gathered on potentially important control variables that could influence the relationship between fish consumption and cognitive functioning. Variables included sex, age, and level of parental education (LPE). 
The latter was defined as the formal schooling level of the parent with the highest educational level achieved [17].

\section{Statistical analyses}

The statistical package SPSS 17.0 was used to perform the statistical analyses. To investigate whether there were differences in fish consumption for sex and educational track $\chi^{2}$ tests were used. To examine whether the four fish consumption groups differed in age or LPE analyses of variance (ANOVA) were used.

Analyses of covariance (ANCOVA) were executed to examine whether the four fish consumption groups differed in attention, vocabulary and/or academic performance while controlling for age, sex, educational track, and LPE. Covariates were tested for the assumption of linearity with the dependent variables. Assumptions of normality were tested within each fish consumption group for each dependent variable separately. Since the four fish consumption groups differed in sample sizes, a correction was made for unequal cell sizes. The $p$-value required for significance was set at $p<.05$.

\section{RESULTS}

\section{Results}

The study was performed in a sample of 786 adolescents who had indicated to be willing to participate in this study. From this group, 86 had to be excluded due to one or more of the following reasons: notably learning problems, psychiatric or developmental disorders with or without medication $(n=10)$, skipping school regularly $(n=7)$, taking fish oil supplements $(n=74)$. This resulted in a final sample of 700 adolescents (394 girls, 306 boys) with a mean 
age of $15.0(S D=1.8)$. Of the participating students, 337 students were enrolled in higher general secondary education, whereas 363 students were enrolled in pre-university education.

[insert Table 1 here]

\section{Fish consumption}

Results showed that $13.7 \%$ of the adolescents aged 12 to 18 never ate fish, while only $6.4 \%$ met the national guidelines of an average DHA and EPA intake of $450 \mathrm{mg}$ per day (see Table 1). In addition, $16.9 \%$ reached at least half of the recommended amount, while the majority $(63.0 \%)$ did eat fish, but rather irregularly or too little to meet at least half of the recommended amount. Fish consumption did not differ between boys and girls, $\chi^{2}(3)=2.95$, ns, and educational track, $\chi^{2}(3)=1.00, \mathrm{~ns}$, neither was it associated with age, $F(3,696)=.39$, ns, nor with LPE, $F(3,694)=.96$, ns.

\section{Differences in attention}

Analysis revealed no significant differences between the fish consumption groups regarding attention problems, $F(3,681)=0.94, p=.42$. Of the covariates, only age was significant, $F(1,681)=6.49, p=.01, \eta_{p}{ }^{2}=.01$. With increasing age, more attention problems were reported (see also Table 2).

[insert Table 2 here]

\section{Differences in vocabulary}

Of the participants, 68 did not complete the vocabulary task resulting in a sample of 632 students for analysis. With respect to vocabulary, significant differences were found between 
the four fish consumption groups, $F(3,624)=2.50, p=.05, \eta_{p}{ }^{2}=.02$, even after controlling for significant effects of the covariates age, $F(1,624)=329.65, p<.001, \eta_{p}{ }^{2}=.35$, and educational track, $F(1,624)=55.54, p<.001, \eta_{p}{ }^{2}=.08$. No significant effects were found for sex, and LPE. Polynomial contrast analyses revealed that the relation between fish consumption and vocabulary was quadratic, contrast $=-0.59, p=.01$. A higher average DHA/EPA intake per week was associated with more advanced vocabulary. However, eating more fish than the prescribed recommended amount seemed no longer to be beneficial. The model explained $40 \%$ of the variance in vocabulary.

\section{Differences in academic performance}

A similar trend for differences between the four fish consumption groups was found regarding academic performance, $F(3,639)=2.35, p=.07, \eta_{p}{ }^{2}=.01$. In this model, the covariates sex, $F(1,639)=11.39, p=.001, \eta_{p}{ }^{2}=.02$, educational track, $F(1,639)=41.08, p<.001, \eta_{p}{ }^{2}=.06$, and

LPE, $F(1,639)=11.57, p=.001, \eta_{p}{ }^{2}=.02$, were significant, whereas age was not, $F(1,639)=2.43$, $p=.12$. Polynomial contrast analyses demonstrated a significant quadratic association between fish consumption and academic performance, contrast $=-0.20, p=.01$. Academic performance increased with a higher DHA/EPA intake, but not for the group with the highest fish consumption. The model explained $12 \%$ of the variance in academic performance. 


\section{DISCUSSION}

The aim of this study was to investigate the association between fish consumption and cognitive performance measured by vocabulary scores, self-reported attention scores, and academic achievement. A significant inverted U-shape association between fish consumption and vocabulary scores as well as a trend for an inverted U-shape for academic achievement was found. This suggests that higher fish consumption is associated with better vocabulary scores as well as better academic achievement. However, as soon the advised recommended amount of $450 \mathrm{mg}[14] \mathrm{EPA} / \mathrm{DHA}$ per day is exceeded, fish consumption was associated with lower vocabulary scores and lower academic achievement. Self-reported attention scores were not associated with fish consumption.

In the Netherlands, little data is available on fish consumption of adolescents. The most recent available data concern data from the food consumption sounding held in 2003 under 750 participants aged 19-30 years [18]. It found that only $19 \%$ of the population questioned consumed any fish. This resulted in an estimated average intake of only $8 \mathrm{~g} / \mathrm{d}$ for the whole population, although the researchers also remark that this was not measured in a valid and reliable way. Our findings are representative for fish and seafood intake of Dutch adolescents aged 12 to 18 years old. The number of adolescents in this age group consuming any fish is much larger than that reported by Hulshof et al [18]. Of the adolescents in our study, $86 \%$ consumed fish every now and then. However, the number of Dutch high school students in our study who reached the national guidelines [14] of $450 \mathrm{mg}$ of DHA/EPA consumption per day was only $6.4 \%$. This is more in accordance with the 2006 findings in Dutch children aged 2-3 years and 4-6 years of whom 9.5\% and $8 \%$ met the national guidelines respectively [19]. This is not surprising, since most Dutch adolescents stay at home until the age of 18 where their parents/guardians are primarily responsible for their daily food intake. Above, these numbers are in accordance with the numbers reported for Australia [20]. A limitation of the 
current study might be that portion size is not taken into account when estimating fish consumption. However, there is a strong indication that this recently developed short selfreport questionnaire provided a reliable proxy of fish intake, as EPA and DHA concentrations in plasma phospholipids strongly correlated with fish intake [12] even better than correlations between other estimates for fish consumption and plasma concentrations found in other studies [21-23]. It is, thus, convincing that for the first time here a reliable estimate of fish consumption in Dutch adolescents aged 12-18 years is reported.

Higher omega-3 LCPUFA intake was proposed as being associated with higher cognitive performance as well as higher academic achievement. Recently, Kim et al. [10] and Aberg et al. [11] published evidence from a large general population study supporting this. Our results demonstrated that after correction for age, sex, and educational track, higher omega-3 LCPUFA intake was associated with higher vocabulary scores. In addition, academic achievement measured as the average end-term scores of the core subjects Dutch, English, and Mathematics seemed to be higher when more fish was consumed. No significant results were found for scores on the Youth Self Report, implicating that there were no differences between the four fish consumption groups in self-reported attention problems. These results imply that the more fish consumed by the adolescents, the better their objective cognitive performance (vocabulary), as well as their academic achievement. Interestingly, quadratic associations, meaning that as soon as the adolescents in our population consumed more DHA/EPA than the recommended amount of $450 \mathrm{mg} / \mathrm{d}$, were found. This was associated with significantly lower scores on vocabulary and academic achievement.

Thus, our findings suggest that irrespective of sex, age, and educational track, the association between fish consumption and cognitive performance and academic achievement in adolescents consist of an inverted U-shape. 
These results are for the most part in line with two previous studies. Aberg et al found that frequent fish intake as compared to infrequent fish intake at age 15 in boys was associated with significantly higher cognitive performance as measured by combined intelligence, verbal skills, and visuospatial skills three years later [11]. Kim et al showed that after adjusting for sex and socioeconomic status, fish consumption among school children aged 15 years was significantly associated with higher school grades [10]. An important difference with our study, however, was that both studies divided fish consumption into only three categories in which the highest category represented eating fish more than once a week. Twice weekly fish consumption (red. thus more than once a week) equals the recommended amount of $450 \mathrm{mg}$ EPA/DHA per day. We distinguished a fourth fish consumption group, namely more than the recommended amount. Although the number of persons in this group is considerably lower than in the other groups, it adds a special dimension to the study. And, to some extent unexpectedly, these findings suggest that if more fish is consumed than the advised amount of $450 \mathrm{mg}$ EPA/DHA daily, there is a negative association with vocabulary and academic achievement.

This, however, is not the first negative association found between fish consumption and cognitive performance. Previously, our group reported negative correlations between DHA in plasma phospholipids and selective attention in pregnant women and young mothers [24]. Although selective attention represents another cognitive domain, it is still an indication of a negative association between intake and cognitive functioning. Another study revealed preliminary indications that a higher plasma phospholipid DHA status in healthy nonpregnant women was associated with slower learning curves [25]. Although we take into account that associative studies do not answer any causality issues, we think the time is right to pay attention to possible negative consequences of 'overconsumption' of omega-3 PUFA or fish. 
A possible explanation might be that, in the case of consumption of fish more than twice a week, persons are exposed with too many toxic substances present in fish. Fish intake involves the involuntary but unavoidable intake of unwanted substances such as heavy metals (e.g., mercury, cadmium, etc.) and leftovers of difficult to degrade substances (e.g., PCBs, dioxins). However, this hypothesis cannot be substantiated by the two earlier studies, because the results of those studies were not based upon fish consumption data but upon pure DHA concentrations in plasma phospholipids. The only way that conclusive evidence can be arrived at is through an intervention study. As far as we are aware of, this kind of thorough scientific research into the effects of n-3 LCPUFA on cognitive performance of healthy adolescents within the general population, without any pathology (i.e., ADHD, schizophrenia) is lacking. Although fish consumption is only a proxy for the actual fatty acid status, our observations indicate that the association between fish consumption and both cognitive performance and academic achievement in adolescents aged 12-18 years consists of an inverted U-shape. The differences found between the groups (e.g. for academic performance) could be relevant for educational practice. To calculate academic performance, we made use of standardized zscores in order to correct for possible grading policies of schools. The difference in z-score between the $1575-3150 \mathrm{mg}$ fish group and the highest fish consumption group is 0.29 (.14 - .15 ). This equals $0.29 * .81$ (raw population SD) 0.23 points differences on a 10 point scale (Dutch grades are not given in letters, but in numbers between 0-10). This difference in fish consumption could therefore account for the difference between passing or failing. Further prospective observational studies with repeated measures are required to confirm these findings, but ultimately interventions studies are required to determine the causality of this association. In the meantime, it seems prudent to advise adolescents to consume fish twice a week, but not more than that. 


\section{ACKNOWLEDGEMENTS}

The authors gratefully acknowledge Gerard Hornstra for critically reviewing the manuscript.

In addition they would like to express their gratitude to Wim van der Elst for providing statistical help. 


\section{REFERENCES}

[1] A. Assisi, R. Banzi, C. Buonocore et al., Fish oil and mental health: the role of n-3 long-chain polyunsaturated fatty acids in cognitive development and neurological disorders, Int Clin Psychopharmacol 21 (2006) 319-336.

[2] M.C. Morris, D.A. Evans, C.C. Tangney, J.L. Bienias, R.S. Wilson, Fish consumption and cognitive decline with age in a large community study, Arch Neurol 62 (2005) 15.

[3] M.C. Morris, D.A. Evans, J.L. Bienias et al., Consumption of fish and n-3 fatty acids and risk of incident Alzheimer disease, Arch Neurol 60 (2003) 940-946.

[4] R. Uauy, D.R. Hoffman, Essential fat requirements of preterm infants, Am J Clin Nutr 71 (2000) 245S-250S.

[5] C.M. Milte, N. Sinn, P.R. Howe, Polyunsaturated fatty acid status in attention deficit hyperactivity disorder, depression, and Alzheimer's disease: towards an omega-3 index for mental health?, Nutr Rev 67 (2009) 573-590.

[6] N. Gogtay, J.N. Giedd, L. Lusk et al., Dynamic mapping of human cortical development during childhood through early adulthood, Proc Natl Acad Sci U S A 101 (2004) 8174-8179.

[7] P.S. Sastry, Lipids of nervous tissue: composition and metabolism, Prog Lipid Res 24 (1985) 69-176.

[8] L. Svennerholm, Distribution and fatty acid composition of phosphoglycerides in normal human brain, J Lipid Res 9 (1968) 570-579.

[9] R.K. McNamara, J. Able, R. Jandacek et al., Docosahexaenoic acid supplementation increases prefrontal cortex activation during sustained attention in healthyboys: a placebo-controlled, dose ranging, functional magnetic resonance imaging study, American Journal of Clinical Nutrition 91 (2010) 1060-1067.

[10] J.L. Kim, A. Winkvist, M.A. Aberg et al., Fish consumption and school grades in Swedish adolescents: a study of the large general population, Acta Paediatr 99 (2010) $72-77$.

[11] M.A. Aberg, N. Aberg, J. Brisman, R. Sundberg, A. Winkvist, K. Toren, Fish intake of Swedish male adolescents is a predictor of cognitive performance, Acta Paediatr 98 (2009) 555-560.

[12] R.H.M. De Groot, M.P.J. Van Boxtel, O.J. Schiepers, G. Hornstra, J. Jolles, Age dependence of plasma phospholipid fatty acid levels: potential role of linoleic acid in the age-associated increase in docosahexaenoic acid and eicosapentaenoic acid concentrations, Br J Nutr 102 (2009) 1058-1064.

[13] NEVO-jaartabel 2003 Uitgeverij Stichting NEVO, Zeist, 2003.

[14] H.C.o.t. Netherlands, Guidelines for a healthy diet 2006. Health Council of the Netherlands, The Hague, 2006

[15] A. Boschloo, A.C. Krabbendam, A. Aben et al., Sex differences in vocabulary and school performance in dolescence, Learning and Individual Differences under revision (2011)

[16] F.C. Verhulst, J. van der Ende, R.F. Ferdinand, M.C. Kasius, The prevalence of DSMIII-R diagnoses in a national sample of Dutch adolescents, Arch Gen Psychiatry 54 (1997) 329-336.

[17] S.E. De Bie, Standaardvragen 1987: Voorstellen voor uniformering van vraagstellingen naar achtergrondkenmerken en interviews [Standard questions 1987: Proposal for uniformisation of questions regarding background variables and interviews]. Leiden University Press, Leiden, The Netherlands, 1987. 
[18] K.F.A.M. Hulshof, M.C. Ocke, C.T.M. Van Rossum et al., Resultaten van de Voedselconsumptiepeiling 2003. Rijksinstituut voor Volksgezondheid en Milieu (RIVM), Bilthoven, 2003111.

[19] E.C. Wilson-Van den Hooven, J.M.A. Van Raaij, M.C. Ocke, C.T.M. Van Rossum, H. Verhagen, Visuele weergave van de voedingssituatie in nederland: een instrument. Rijksinstituut voor Volksgezondheid en Milieu (RIVM), Bilthoven, 200835.

[20] B.J. Meyer, N. Kolanu, Australian children are not consuming enough long-chain omega-3 polyunsaturated fatty acids for optimal health, Nutrition 27 (2011) 11361140 .

[21] S. Kalmijn, M.P. van Boxtel, M. Ocke, W.M. Verschuren, D. Kromhout, L.J. Launer, Dietary intake of fatty acids and fish in relation to cognitive performance at middle age, Neurology 62 (2004) 275-280.

[22] K. Mina, L. Fritschi, M. Knuiman, Do aggregates of multiple questions better capture overall fish consumption than summary questions?, Public Health Nutr 11 (2008) 196202.

[23] R.K. Woods, R.M. Stoney, P.D. Ireland et al., A valid food frequency questionnaire for measuring dietary fish intake, Asia Pac J Clin Nutr 11 (2002) 56-61.

[24] R.H.M. De Groot, J. Adam, J. Jolles, G. Hornstra, Alpha-linolenic acid supplementation during human pregnancy does not effect cognitive functioning, Prostaglandins Leukot Essent Fatty Acids 70 (2004) 41-47.

[25] R.H.M. De Groot, G. Hornstra, J. Jolles, Exploratory study into the relation between plasma phospholipid fatty acid status and cognitive performance, Prostaglandins Leukot Essent Fatty Acids 76 (2007) 165-172. 


\section{Tables}

Table 1. Characteristics and performance of the four fish consumption groups based on the average DHA/EPA intake per week (mean $\pm \mathrm{SD}$, unless otherwise indicated)

\begin{tabular}{|l|c|c|c|c|}
\hline & Group 1: & Group 2: & Group 3: & Group 4: \\
& no intake & $<1575 \mathrm{mg}$ & $1575-$ & $>3150 \mathrm{mg}$ \\
\hline $\mathrm{n}(\%)$ & $96(13.7)$ & $441(63.0)$ & $118(16.9)$ & $45(6.4)$ \\
\hline \multicolumn{1}{|c|}{ Baseline } & & & & \\
\hline Age (yr.) & $15.1(1.7)$ & $14.9(1.8)$ & $15.1(1.8)$ & $15.2(1.9)$ \\
\hline Gender (\% male) & 37.5 & 46 & 41.5 & 40 \\
\hline Educational track (\% HGSE) & 45.8 & 49.4 & 44.9 & 48.8 \\
\hline LPE (measured by 8-point scale) & $5.5(1.3)$ & $5.6(1.4)$ & $5.8(1.2)$ & $5.6(1.7)$ \\
\hline \multicolumn{1}{|c|}{ Outcome } & & & & \\
\hline Attention problems & $4.61(3.23)$ & $4.97(3.01)$ & $5.21(3.41)$ & $4.57(3.08)$ \\
\hline Vocabulary & $28.34(2.95)$ & $28.53(2.72)$ & $29.10(2.71)$ & $28.17(3.13)$ \\
\hline Academic Performance & $-.10(.86)$ & $.02(.77)$ & $.14(.78)$ & $-.15(.75)$ \\
\hline
\end{tabular}

Notes. HGSE=higher general secondary education, LPE=level of parental education 
Table 2. Zero-order Pearson correlations between main variables $(N=700)$

\begin{tabular}{|l|l|l|l|l|l|l|}
\hline & 1 & 2 & 3 & 4 & 5 & 6 \\
\hline 1. Attention problems & - & & & & & \\
\hline 2. Vocabulary & .02 & - & & & & \\
\hline 3. Academic performance & $-.22^{* *}$ & $.12^{* *}$ & - & & & \\
\hline 4. Age & $.11^{* *}$ & $.56^{* *}$ & -.04 & - & & \\
\hline 5. Sex & -.02 & -.02 & $.12^{* *}$ & .05 & - & \\
\hline 6. Educational track & -.06 & $.27^{* *}$ & $.28^{* *}$ & $.11^{* *}$ & .01 & - \\
\hline 5. LPE & -.06 & .03 & $.21^{* *}$ & $.10^{*}$ & -.02 & $.29 * *$ \\
\hline
\end{tabular}

Notes. LPE $=$ Level of Parental Education, ${ }^{*} \mathrm{p}<.05,{ }^{*} \mathrm{p}<.01$ 